\title{
A Nonwounding Greenhouse Screening Protocol for Prediction of Field Resistance of Hybrid Poplar to Septoria Canker
}

Ruqian Qin, Department of Plant Pathology, North Dakota State University, Fargo 58108; Glen R. Stanosz, Department of Forest and Wildlife Ecology, University of Wisconsin-Madison, Madison 53706; and Jared M. LeBoldus, Department of Plant Pathology, North Dakota State University, Fargo

\begin{abstract}
Qin, R., Stanosz, G. R., and LeBoldus, J. M. 2014. A nonwounding greenhouse screening protocol for prediction of field resistance of hybrid poplar to Septoria canker. Plant Dis. 98:1106-1111.

Populus spp. and their hybrids are short-rotation woody crops which supply fiber to a diversity of industries in North America. The potential of hybrid poplar trees has been limited by the fungal pathogen Septoria musiva, the cause of leaf spot and stem canker of Populus spp. An inoculation protocol that does not rely on stem wounding to achieve infection was recently developed to screen poplar clones for resistance to Septoria canker. Prior to this study, the relationship between results obtained using this inoculation protocol and long-term field resistance of clones was unknown. Young ramets of 14 clones of hybrid poplar that were previously assigned to long-term canker damage categories

(low, intermediate, and high) were inoculated with a conidial suspension of three isolates of $S$. musiva under greenhouse conditions. Three weeks post inoculation, lesion number, lesions per centimeter of stem length, area of stem that was necrotic, and proportion of stem area that was necrotic were measured. Logistic regression with lesion number and proportion necrotic area correctly predicted long-term disease damage categories for 11 of 14 clones tested, including the most resistant (NM6) and the most susceptible (NC11505) clones, demonstrating that this screening protocol is a promising method for prediction of long-term disease impact of the most resistant clones.
\end{abstract}

Populus spp. and their hybrids are an important forest resource in North America (4). Trees in this genus are ideal for short-rotation woody cropping (SRWC) systems due to their ease of propagation, phenotypic uniformity, and high growth rates $(7,16,34)$. Plantations of Populus trees are currently being used for fiber, value-added forest products, and are a potential biofuel feedstock $(3,8,13,21,22,31,34,35)$. However, the growth and yield of Populus spp. and their hybrids grown in SRWC systems are often impacted by several important diseases $(16,19,39)$. In the north-central and eastern regions of North America, the leaf spot and canker diseases caused by Mycosphaerella populorum G.E. Thomps. (anamorph = Septoria musiva Peck) have had the greatest impact $(4,25,37,39)$. The recent expansion of this pathogen into poplar-producing regions such as the Fraser Valley in British Columbia, Canada (6) and South America (33) further highlight the importance of this pathogen.

Septoria leaf spot can impact growth and yield by reducing the leaf area available for photosynthesis, and may cause premature defoliation of highly susceptible genotypes (clones; 4,25,37,39). Cankers may kill distal portions of branches and stems. Stem cankers are defects that reduce economic value, increase the risk of breakage, and may result in plantation failure by killing highly susceptible clones $(4,25,27,28,39)$. The importance of Septoria canker has resulted in several studies of the effectiveness of different management strategies. These studies indicated that cultural, biological, or chemical controls are either too expensive or have limited efficacy $(11,29,43)$. Therefore, the selection and deployment of diseaseresistant clones is the most effective way to manage this disease (29).

Early observations by Bier (4) and Waterman (39) indicated a relationship between response of clones to inoculation and Septoria canker damage in the field. More recently, Weiland et al. (41) inoculated young stems of poplar clones by placing mycelial plugs on

Corresponding author: J. LeBoldus, E-mail: jared.leboldus@ndsu.edu

Accepted for publication 5 March 2014.

http://dx.doi.org/10.1094/PDIS-11-13-1152-RE

(C) 2014 The American Phytopathological Society wounds produced by removing a leaf. Clones had been categorized according to previously observed Septoria canker damage severity. Results were predictive of long-term damage categories in both field ( 24 of 27 clones) and potted trees in the greenhouse (14 of 15 clones) experiments.

Although the feasibility and potential benefit of screening juvenile poplar clones was demonstrated, the procedures of Weiland et al. (41) have possible disadvantages. Inoculum plugs bore a single pathogen isolate, which may limit the potential for detecting a clone-isolate interaction. Given the ability of the pathogen to reproduce sexually (10) and the clone-isolate interaction detected by other researchers $(14,15,38)$, the use of multiple isolates increases the probability of selecting the most durable resistance under field conditions. Inoculation of wounds circumvents potential resistance mechanisms. Numbers of clones and replicates are limited by available space if screening is done with multiple isolates and trees are inoculated with a single isolate, as described by Weiland et al. (41,42). LeBoldus et al. (15) described an inoculation protocol in which very young, nonwounded ramets were inoculated with a conidial suspension in the greenhouse. This allowed multiple isolates to be used simultaneously, and produced results correlated with clonal responses to wound inoculation in a relatively short period of time (15). However, the ability of this protocol to predict long-term field performance of resistant and susceptible clones was not tested.

The current study was conducted using 14 clones of hybrid poplar assigned to long-term canker damage categories by Weiland et al. $(41,42)$, based on multiple observations of these clones across regions (Table 1; 1,12,13,18,19,24,26,28,29,36). Clones were not wounded and were inoculated with a multiple-isolate conidial suspension. The goal was to improve and increase the practicality of greenhouse screening of hybrid poplar clones for resistance to Septoria canker. The specific objectives were to (i) test the predictive ability of this inoculation protocol for prediction of long-term canker damage categories and (ii) determine which disease severity parameters were best used for prediction.

\section{Materials and Methods}

Host plant propagation. Fourteen hybrid poplar clones categorized according to previously observed Septoria canker damage 
categories $(41,42)$, were propagated from dormant branches collected in February 2012 at the University of Wisconsin-Madison Arlington Agricultural Research Station in Arlington, WI (Table 2). Cuttings (10 cm long) were soaked in distilled water for $48 \mathrm{~h}$ at room temperature $\left(21^{\circ} \mathrm{C}\right)$ and then planted in SC10 Super conetainers (Stuewe \& Sons Deepots D40 cell; Stuewe \& Sons Inc.) containing SunGro growing medium (SunGro Professional Mix number 8; SunGro Horticulture Ltd.) amended with $12 \mathrm{~g}$ of nutricote slow-release fertilizer $(15-9-12, \mathrm{~N}-\mathrm{P}-\mathrm{K})\left(7.0 \% \mathrm{NH}_{3}-\mathrm{N}\right.$, $8.0 \% \mathrm{NO}_{3}-\mathrm{N}, 9.0 \% \mathrm{P}_{2} \mathrm{O}_{5}, 12.0 \% \mathrm{~K}_{2} \mathrm{O}, 1.0 \% \mathrm{Mg}, 2.3 \% \mathrm{~S}, 0.02 \% \mathrm{~B}$, $0.05 \% \mathrm{Cu}, 0.45 \% \mathrm{Fe}, 0.23 \%$ chelated $\mathrm{Fe}, 0.06 \% \mathrm{Mn}, 0.02 \% \mathrm{Mo}$, $0.05 \%$ Zn; Scotts Osmocote Plus; Scotts Company Ltd.). A 500 ppm solution of 20-20-20 liquid fertilizer $\left(3.94 \% \mathrm{NH}_{3}-\mathrm{N}, 6.05 \%\right.$ $\mathrm{NO}_{3}-\mathrm{N}, 10.01 \% \mathrm{CO}\left(\mathrm{NH}_{2}\right)_{2}, 20.0 \% \mathrm{P}_{2} \mathrm{O}_{5}, 20.0 \% \mathrm{~K}_{2} \mathrm{O}, 0.05 \% \mathrm{Mg}$, $0.0068 \% \mathrm{~B}, 0.0036 \% \mathrm{Cu}, 0.05 \%$ Chelated Fe, $0.25 \% \mathrm{Mn}, 0.0009 \%$ Mo, $0.0025 \%$ Zn; Scotts Peters Professional; Scotts Company Ltd.) was subsequently provided weekly. When trees reached a height of $30 \mathrm{~cm}$, they were transplanted into pots $(22 \mathrm{~cm}$ deep by $22.5 \mathrm{~cm}$ in diameter; Stuewe \& Sons Treepot CP59R: Stuewe \& Sons Inc.) planted in the same growth medium and fertilized as described above. Trees were grown in a greenhouse with an 18-h photoperiod supplemented with $600-\mathrm{W}$ high-pressure sodium lamps and a day-and-night temperature regime of 20 and $16^{\circ} \mathrm{C}$, respectively.

Pathogen propagation and inoculation. S. musiva isolates MN7, MN11, and MN23 were isolated from individual branch cankers collected from three different Populus trees (Populus maximowiczii A. Henry, P. trichocarpa Torr. \& Gary $\times P$. deltoides Marsh, and $P$. deltoides $\times P$. trichocarpa, respectively) located in different plantings near Garfield, $\mathrm{MN}$ in 2012. The cankers were soaked in 5\% bleach ( $\mathrm{NaClO} 6 \%$; Homelife Bleach Regular Scent; KIK Custom Products Inc.) for 2 min and rinsed twice with sterile distilled water. Bark was removed to expose the margin between healthy and necrotic tissue. From this area, a 4-mm-long sliver of necrotic tissue was removed and placed on V8 juice agar $(137 \mathrm{ml}$ of V8 juice [Campbell Soup Company], $1.5 \mathrm{~g}$ of $\mathrm{CaCO}_{3}$ [ReagentPlus; Research Organics Inc.], $15.2 \mathrm{~g}$ of agar [Difco], and 625 $\mathrm{ml}$ of deionized water) in petri plates. Subsequently, petri plates were sealed with Parafilm (BRAND GMBH + CO KG) and incubated at room temperature in constant light $30 \mathrm{~cm}$ below Gro-Lux full-spectrum fluorescent bulbs (Sylvania; Osram $\mathrm{GmbH}$ ). After approximately 1 week, transfers were made to a second V8 juice agar plate. Identity of pure cultures was confirmed on the basis of conidial morphology (33). Isolates were stored at $-80^{\circ} \mathrm{C}$ in vials containing $1 \mathrm{ml}$ of a $50 \%$ glycerol solution.

Inoculum of each of the three isolates was produced from vials removed from cold storage. Each vial was poured onto a petri plate containing V8 juice agar and placed under light, as described above, for 5 days. Then, four 5-mm-diameter sporulating masses of mycelium were aseptically transferred to each of 13 new plates of V8 juice agar for each isolate. These plates were then placed under light as described above to induce sporulation. Conidia were harvested after 14 days by flooding each plate with $5 \mathrm{ml}$ of sterile distilled water, rubbing the surface with a sterile loop, and removing the resulting spore suspension with a micropipette. The spore suspensions for all 13 plates of each isolate were combined and the

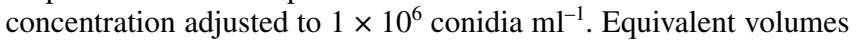
of each of the three conidial suspensions (MN7, MN11, and MN23) were then combined to conduct bulk inoculations. Inoculum for both trials was prepared in an identical manner.

Approximately 2 weeks after transplanting, stem height was measured. Trees were then removed from the greenhouse and each stem was sprayed with the conidial suspension (approximately 15 $\mathrm{ml}$ tree $^{-1}$ ), placed in separate black plastic bags at $21^{\circ} \mathrm{C}$. After $48 \mathrm{~h}$, plants were removed from the bags and returned to the greenhouse (15). Twenty-one days after inoculation, disease severity was evaluated. Lesion number (lesion $n$ ) was a count of the number of necrotic lesions per stem. Lesions per centimeter was calculated by

Table 1. Number of field sites, number of clones, observation period, and tree age of the seven field studies used to develop the Septoria canker disease damage categories for the 14 hybrid poplar clones used in this study

\begin{tabular}{|c|c|c|c|c|}
\hline Reference & Number of field sites & Numbers of clones & Observation period & Tree age \\
\hline Schreiner (32) & 2 & 40 & 1970 to 1971 & 15 to 20 years old \\
\hline Hansen et al. (12) & 3 & 34 & 1976 to 1981 & $\ldots$ \\
\hline Hansen et al. (13) & 30 & $40-80$ & 1991 to 1992 & 5 to 6 years old \\
\hline Abrahamson et al. (1) & 1 & 54 & 1986 to 1987 & 3 years old \\
\hline Lo et al. (18) & 1 & 54 & 1993 & 9 years old \\
\hline Netzer et al. (24) & 16 & 95 & 1987 to 1992 & 7 to 12 years old \\
\hline Ostry and McNabb (28) & 3 & 34 & 1976 to 1982 & 5 years old \\
\hline
\end{tabular}

Table 2. Poplar clones, parentage, assigned damage categories, and mean and standard deviation of disease severity parameters (Lesion $n$, Lesion/cm, NA, and PNA) of 14 clones inoculated with a bulk spore suspension of three different isolates of Septoria musiva

\begin{tabular}{|c|c|c|c|c|c|c|}
\hline \multirow[b]{2}{*}{ Clone } & \multirow[b]{2}{*}{ Parentage $^{b}$} & \multirow[b]{2}{*}{ Category $^{c}$} & \multicolumn{4}{|c|}{$\operatorname{Mean}(\mathbf{S D})^{\mathrm{a}}$} \\
\hline & & & Lesion $n$ & Lesion/cm & $\mathrm{NA}\left(\mathrm{cm}^{2}\right)$ & PNA \\
\hline NM6 & $4 \times 3$ & $\mathrm{~L}$ & $1.6(3.0)$ & $0.1(0.1)$ & $0.6(1.0)$ & $0.00(0.00)$ \\
\hline DN74 & $2 \times 4$ & $\mathrm{~L}$ & $3.8(3.4)$ & $0.2(0.2)$ & $1.2(0.8)$ & $0.00(0.00)$ \\
\hline DN34 & $2 \times 4$ & $\mathrm{~L}$ & 7.1 (11.6) & $0.2(0.3)$ & $2.1(1.8)$ & $0.01(0.01)$ \\
\hline DN164 & $2 \times 4$ & $\mathrm{~L}$ & $7.8(10.2)$ & $0.4(0.4)$ & $2.3(1.2)$ & $0.01(0.01)$ \\
\hline DN177 & $2 \times 4$ & $\mathrm{~L}$ & $17.8(13.0)$ & $0.5(0.3)$ & $8.8(5.5)$ & $0.02(0.01)$ \\
\hline NC5260 & $9 \times 1$ & I & $4.6(5.5)$ & $0.4(0.3)$ & $1.7(0.6)$ & $0.01(0.00)$ \\
\hline NE222 & $2 \times 5$ & I & $9.2(7.2)$ & $0.3(0.2)$ & $6.2(5.9)$ & $0.02(0.01)$ \\
\hline NC5271 & $7 \times 5$ & I & $13.3(10.6)$ & $0.5(0.2)$ & $10.2(7.8)$ & $0.04(0.03)$ \\
\hline MWH13 & $2 \times 3$ & $\mathrm{H}$ & $7.0(8.8)$ & $0.3(0.2)$ & $4.1(4.5)$ & $0.01(0.02)$ \\
\hline MWH5 & $2 \times 3$ & $\mathrm{H}$ & $3.6(3.4)$ & $0.3(0.1)$ & $1.6(1.1)$ & $0.02(0.00)$ \\
\hline NE308 & $7 \times 6$ & $\mathrm{H}$ & $14.0(7.8)$ & $0.5(0.2)$ & $7.8(3.4)$ & $0.03(0.02)$ \\
\hline NC11432 & $2 \times 8$ & $\mathrm{H}$ & 23.4 (11.7) & $0.8(0.2)$ & $15.0(8.6)$ & $0.05(0.04)$ \\
\hline NE351 & $2 \times 5$ & $\mathrm{H}$ & $24.5(14.0)$ & $0.6(0.1)$ & $14.7(10.3)$ & $0.05(0.04)$ \\
\hline NC11505 & $3 \times 8$ & $\mathrm{H}$ & $39.6(8.8)$ & $1.4(0.2)$ & $40.8(24.4)$ & $0.14(0.07)$ \\
\hline
\end{tabular}

${ }^{a}$ Mean was calculated from 13 individuals of each clone. $\mathrm{SD}=$ standard deviation, calculated from 13 individuals of each clone. Lesion $n=$ number of lesions, Lesion $/ \mathrm{cm}=$ Lesion $n /$ height $(\mathrm{cm}), \mathrm{NA}=$ necrotic area, and proportion necrotic area $(\mathrm{PNA})=\mathrm{NA}\left(\mathrm{cm}^{2}\right) /$ height $\times$ circumference $\left(\mathrm{cm}^{2}\right)$.

${ }^{\mathrm{b}}$ Numbers refer to Populus spp. and hybrids as follows: $1=$ balsamifera, $2=$ deltoides, $3=$ maximowiczii, $4=$ nigra, $5=$ nigra var. caudina, $6=$ nigra var. incrassate, $7=$ nigra var. plantierensis, $8=$ trichocarpa, and $9=$ tristis.

${ }^{c}$ Assigned disease damage categories of Weiland et al. $(41,42)$ : $\mathrm{L}=$ low, $\mathrm{I}=$ intermediate, and $\mathrm{H}=$ high. 
dividing lesion number by the height of the tree at the time of inoculation. The necrotic area (NA) was determined by tracing lesions onto transparencies, digitizing the transparencies, and using Assess 2.0 software (American Phytopathological Society) to measure the necrotic area in square centimeters. The proportion necrotic area (PNA) was calculated by first estimating the stem surface area with the following formula: surface area $=$ height $\times$ circumference. The NA was then divided by the surface area to determine PNA.

Experimental design. The experimental design was a randomized complete block design with six blocks. Each clone occurred once per block. Five of the blocks were inoculated with the conidial suspension and the sixth block (control plants) was sprayed with distilled water. A second trial was conducted with 10 blocks (8 inoculated plus 2 control blocks) using the same methods. In both trials, controls were used to confirm the absence of symptom development and subsequently discarded. Controls were not used in any subsequent statistical analysis.

Statistical analysis. Data from inoculated trees were analyzed using SAS 9.2 (SAS Institute) and significance was assessed at $\alpha=$ 0.05 . Initially, data from both trials were combined. The MIXED procedure in SAS (17), with clone and trial as fixed effects and block as a random effect, was used to test for equality of variances between trials, a significant interaction between clone and trial, and significant differences among main effects. Subsequently, data from each trial were analyzed separately and analyses of each of the four disease severity parameters (Lesion $n$, Lesions $\mathrm{cm}^{-1}$, NA, and PNA) were conducted independently. The MIXED procedure in SAS (17) was used to calculate the mean for each clone-disease severity parameter combination. The models used for mean estimation had clone as a fixed effect and block as a random effect, and the repeated statement was used to model heterogeneous variances among clones. The means were then averaged across the two trials and used in the subsequent multinomial logistic regression analysis.

Fifteen separate logistic regression models (Table 3) were compared in a two-stage process: (i) fit of the model and (ii) predictive power of the fitted model. In the first stage, models were compared using the deviance statistic (2). This statistic is used to compare a reduced model to the saturated model. It is assumed that the saturated model perfectly fits the data and that a reduced model will fit the data to a greater or lesser extent depending on the parameters included in that model. The larger the $P$ value of the deviance statistic, the closer the reduced model is to the saturated model and the better the corresponding fit. In the second stage, the predictive power of the models were compared using the proportion of accurately predicted genotypes, percent concordance (\%CC), percent discordance (\%DC), Gamma, Tau-a, Somer's D, and the $c$ statistic. $\% \mathrm{CC}$ and \%DC represent how the predicted values are associated with the observed values (2). The \% DC and \%CC are calculated by comparing all possible pairs of observations. A pair is concordant if the observation with the larger value of $\mathrm{Y}$ also has a larger value for $\mathrm{X}$. A pair is discordant if the observation with the larger value of $\mathrm{Y}$ has a smaller value of $\mathrm{X}$. Y and $\mathrm{X}$ are defined as the predicted and the observed values, respectively. For all four statistics ( $c$ statistic, Tau-a, Gamma, and Somer's D), the larger the calculated value, the higher the predictive power of the model.

\section{Results}

Necrotic lesions were first observed 2 to 3 weeks following inoculation. Latent period varied among clones and was shorter for more susceptible clones. Lesions were similar in appearance to incipient Septoria cankers observed in the field, and first appeared as small, elliptical areas of water-soaked cells on the surface of stems. These water-soaked areas became necrotic and coalesced to girdle the stem of susceptible clones. Occasionally, the lesions bore pycnidia in light tan centers surrounded by black margins. The majority of lesions developed on the lower third of inoculated trees in association with lenticels and stipules. On highly susceptible clones, however, cankers also developed due to direct penetration (i.e., at sites other than lenticels or stipules) on stems. Approximately 2 weeks after inoculation, swelling developed along the margin of necrotic and healthy tissue, preventing further canker expansion on stems of resistant clones. No symptoms developed on control trees. Controls were not included in any further analysis.

The variances of the two trials were statistically similar and there was no significant clone-trial interaction across the four parameters. However, there were significant differences between trial 1 and 2 for Lesion $n(P<0.001)$, Lesions $\mathrm{cm}^{-1}(P<0.001)$, and NA $(P=0.002)$ but not PNA $(P=0.114)$. As a result, each trial was analyzed separately and the means of each clone-disease severity parameter combination were estimated (Table 2). The analysis indicated that there were significant differences among

Table 3. Goodness-of-fit (deviance) and predictive ability (proportion accurately predicted, percent concordant, percent disconcordant, Somer's D, Gamma, Tau-a, and $c$-statistic) results from logistic regression analysis of data from the 14 clones inoculated with Septoria musiva

\begin{tabular}{|c|c|c|c|c|c|c|c|c|}
\hline Model & Dev. $P>\chi^{2 \mathrm{a}}$ & Overall proportion $^{b}$ & $\% \mathrm{CC}^{\mathrm{c}}$ & $\% \mathrm{DC}^{\mathrm{d}}$ & $\mathbf{S D}^{\mathbf{e}}$ & Gamma $^{f}$ & Tau-ag & $C^{\mathrm{h}}$ \\
\hline $\begin{array}{l}\text { Lesion } n+\text { Lesion } \mathrm{cm}^{-1}+\mathrm{NA} \\
+ \text { PNA }\end{array}$ & 0.54 & $10 / 14$ & 90.5 & 9.5 & 0.81 & 0.81 & 0.56 & 0.91 \\
\hline Lesion $n+\mathrm{NA}+\mathrm{PNA}$ & 0.58 & $10 / 14$ & 88.9 & 11.1 & 0.78 & 0.78 & 0.54 & 0.89 \\
\hline Lesion $n+$ Lesion $\mathrm{cm}^{-1}+\mathrm{NA}$ & 0.49 & $9 / 14$ & 85.7 & 14.3 & 0.71 & 0.71 & 0.50 & 0.86 \\
\hline Lesion/cm + NA + PNA & 0.55 & $9 / 14$ & 84.1 & 15.9 & 0.68 & 0.68 & 0.47 & 0.84 \\
\hline Lesion $n+$ Lesion $\mathrm{cm}^{-1}+$ PNA & 0.60 & $11 / 14$ & 88.9 & 11.1 & 0.78 & 0.78 & 0.54 & 0.89 \\
\hline Lesion $n+\mathrm{NA}$ & 0.52 & $9 / 14$ & 84.1 & 15.9 & 0.68 & 0.68 & 0.47 & 0.84 \\
\hline Lesion $\mathrm{cm}^{-1}+\mathrm{NA}$ & 0.49 & $8 / 14$ & 77.8 & 22.2 & 0.56 & 0.56 & 0.39 & 0.78 \\
\hline $\mathrm{NA}+\mathrm{PNA}$ & 0.61 & $10 / 14$ & 82.5 & 17.5 & 0.65 & 0.65 & 0.45 & 0.83 \\
\hline Lesion $\mathrm{cm}^{-1}+$ PNA & 0.53 & $9 / 14$ & 77.8 & 22.2 & 0.56 & 0.56 & 0.39 & 0.78 \\
\hline Lesion $n+$ PNA & 0.63 & $11 / 14$ & 88.9 & 11.1 & 0.78 & 0.78 & 0.54 & 0.89 \\
\hline Lesion $n+$ Lesion $\mathrm{cm}^{-1}$ & 0.41 & $8 / 14$ & 71.4 & 28.6 & 0.43 & 0.43 & 0.30 & 0.71 \\
\hline Lesion $n$ & 0.45 & $8 / 14$ & 71.4 & 28.6 & 0.43 & 0.43 & 0.30 & 0.71 \\
\hline Lesion/cm & 0.46 & $7 / 14$ & 69.8 & 28.6 & 0.42 & 0.42 & 0.29 & 0.71 \\
\hline NA & 0.52 & $8 / 14$ & 71.4 & 28.6 & 0.43 & 0.49 & 0.30 & 0.71 \\
\hline PNA & 0.59 & $8 / 14$ & 79.4 & 20.6 & 0.59 & 0.587 & 0.41 & 0.80 \\
\hline
\end{tabular}

a $P$-value of the deviance statistic for the Goodness-of-fit test.

b Proportion of clones which are accurately predicted in the greenhouse experiment.

c Percent concordant; a pair of observations is concordant if the observation with the larger value of $\mathrm{Y}$ also has a larger value for $\mathrm{X}$ ( $\mathrm{Y}$ and $\mathrm{X}$ are the predicted and the observed values, respectively).

d Percent discordant; a pair of observations is discordant if the observation with the larger value of $\mathrm{Y}$ has a smaller value for $\mathrm{X}$ ( $\mathrm{Y}$ and $\mathrm{X}$ are the predicted and the observed values, respectively).

e Somer's D $=(\% \mathrm{CC}-\% \mathrm{DC}) /(\% \mathrm{CC}+\% \mathrm{DC}-\mathrm{T})$.

${ }^{\mathrm{f}} \mathrm{Gamma}=(\% \mathrm{CC}-\% \mathrm{DC}) /(\% \mathrm{CC}+\% \mathrm{DC})$.

$\mathrm{g}$ Tau-a $=(\% \mathrm{CC}-\% \mathrm{DC}) / \mathrm{N}$, where $\mathrm{N}=$ total number of pairs.

h $c$-Statistics; $c=0.5 \times(1+\mathrm{SD})$. 
clones across all four parameters in both trials $\left(P_{\text {Lesion } n}<0.001\right.$, $P_{\text {Lesions cm }}{ }^{-1}<0.001, P_{\mathrm{NA}}<0.001$, and $\left.P_{\mathrm{PNA}}<0.001\right)$. NM6 was the most resistant clone and $\mathrm{NC} 11505$ was the most susceptible clone regardless of disease severity parameters (Table 2). The average number of lesions per clone ranged from 1.6 for NM6 to 39.6 for $\mathrm{NC} 11505$, the mean number of Lesions $\mathrm{cm}^{-1}$ ranged from 0.1 for NM6 to 1.5 for NC11505, the mean NA ranged from $0.6 \mathrm{~cm}^{2}$ for NM6 to $40.8 \mathrm{~cm}^{2}$ for NC11505, and the PNA ranged from 0.01 for NM6 to 0.14 for NC11505 (Table 2). In order to develop models to predict long-term disease damage categories based on the nonwounded inoculation protocol, means for each clone-disease severity parameter combination were averaged across both trials.

Across the 15 tested models, four low-damage category clones (DN74, DN34, MWH5, and NM6) and five high-damage category clones (NC11432, NC11505, NC5271, NE308, and NE351) were correctly predicted to be resistant and susceptible, respectively (Table 4). The model with Lesion $n$ and PNA as explanatory variables had the best fit, relative to the saturated model $(P=0.63$; Table 3). Somer's D (0.78), Gamma (0.78), Tau-a (0.54), and the $c$ statistic (0.89) indicated that this model had the highest predictive power relative to all but one of the other models. Only the full model (Lesion $n+$ Lesion $\mathrm{cm}^{-1}+\mathrm{NA}+\mathrm{PNA}$ ) had greater predictive ability (Table 3 ). However, the proportion of accurately predicted clones for the model with Lesion $n+$ PNA (11 of 14) was greater than the full model's (10 of 14).

\section{Discussion}

Inoculation of poplar trees with conidia of S. musiva has produced varying results in previous studies. Lesions that developed in the current study were similar in appearance to those observed on inoculated $P$. balsamifera trees by Zalasky (44) and LeBoldus (15). Bier (4) used similar methods to induce stem lesion development at the base of leaves and surrounding lenticels of nonwounded hybrid poplar clones. Krupinsky (14) reported that a small number of cankers developed on young succulent tissue of the most susceptible clones. In contrast, cuttings of NE338 (NC11505 in this study), a highly susceptible clone, did not develop stem lesions after inoculation with a conidial suspension by Long et al. (19). A consistent difference, based on the above authors' descriptions, between three of the studies in which stem lesions developed $(14,15,44)$ and the one in which that they did not (19) was the age of the trees. Long et al. (19) inoculated 25-week-old trees whereas Zalasky (44), LeBoldus (15), and Krupinsky (14) all inoculated trees $\leq 12$ weeks of age. Bier (4) did not report the age of the trees at the time of inoculation. One possible explanation for the lack of canker development on older trees is the period of time, lasting several weeks, where trees lose their epidermis and develop periderm and phloem fibers (9). During this period of development, the bark (epidermis) is relatively thin and may be more easily penetrated by $S$. musiva (44). As the tree ages, the thickening periderm might prevent infection without prior wounding.

To these authors' knowledge, this study and that of LeBoldus et al. (15) are the only studies where statistically significant differences in susceptibility among clones were detected for trees inoculated by conidial suspension (Table 2). Neither Bier (4) nor Krupinsky (14) reported differences in lesion number or severity on inoculated trees. Although Zalasky (44) indicated that differences in response to inoculation were not apparent among inoculated seedlings, he was unable to make statistical comparisons due to a lack of replication. Not only were significant differences among clones apparent but they also were consistent across the two trials, and they were predictive of long-term field performance.

An examination of the predictive models tested in this study indicates that a measure of both lesion severity and lesion number result in the greatest number of accurately predicted clones. The combination of Lesion $n$ and PNA (Table 3 ) allows the model to take both the number of lesions and the size of those lesions into consideration when predicting long-term damage categories. These results are consistent with Weiland et al. (41), who found that the parameters of canker incidence and girdle had the greatest predic- tive ability in both the greenhouse and field studies in which seedlings were wound inoculated.

There are several possible explanations for the lack of complete predictive ability of this study with the previously assigned damage categories. In the field studies, clones NC5271, NC5260, and NE222 displayed a range of disease severities across regions $(12,18,41,42)$, potentially contributing to uncertainty as to whether their previously assigned canker damage category accurately reflected resistance or susceptibility to Septoria canker. This may have been further exacerbated by the different Septoria canker rating methods used by previous researchers to describe or categorize damage. For example, Lo et al. (18) counted canker number and subsequently placed clones into four classes: $0=$ no canker, 1 = one canker, 2 = two or three cankers, and $3=$ four or more cankers. In contrast, Hansen et al. (12), using a different method to evaluate Septoria canker in the Midwest, placed clones into the following categories: $0=$ no canker, $1=$ branch canker, $2=$ stem cankers, $3=$ stem dieback and breakage by cankers. As a result, clones were placed in different categories by different researchers. For example, NC5271 was placed in the low category by Lo et al. (17) and was placed in the high category by Hansen et al. (11), perhaps explaining placement in the intermediate category by Weiland et al. (41). Another possibility may be the presence of specificity in the pathogen population. Several authors $(14,15,38)$ detected a small but significant clone-isolate interaction in their inoculation assays. This may explain the discrepancy between the predictions of the wound-inoculation protocol and the nonwoundinoculation protocol, both of which used different isolates. However, further exploration of the significance and magnitude of this effect needs to be conducted.

There are two main advantages of the conidial inoculation of nonwounded seedlings. Due to space requirements of screening multiple clones with the wound-inoculation assay, several authors $(15,18,38,41,42)$ have suggested that a single highly virulent isolate could be used to select the most resistant clones for field testing. However, Feau et al. (10) found evidence of sexual reproduction in the pathogen population, suggesting that $S$. musiva virulence may shift in response to the deployment of resistant genotypes. The ability of the pathogen to reproduce sexually and the potential presence of a clone-isolate interaction, described above $(14,15,38)$, suggests that using multiple isolates to screen for resistance is more likely to select the most durable resistance under field conditions. The second advantage is the cost savings associated with conducting a preliminary greenhouse screening. Disease

Table 4. Predicted damage category and the probability of placement in the categories using the final model, contrasted with the assigned damage category for each of the 14 clones $^{\mathrm{a}}$

\begin{tabular}{lcccccc}
\hline & \multicolumn{2}{c}{ Damage category } & & \multicolumn{3}{c}{ Probability of placement $(\boldsymbol{\%})^{\mathbf{c}}$} \\
\cline { 2 - 3 } \cline { 5 - 6 } Clone & Assigned & Predicted & & L & I & H \\
\hline NM6 & L & L & & 49 & 33 & 18 \\
DN74 & L & L & & 57 & 29 & 14 \\
DN34 & L & L & & 71 & 21 & 8 \\
DN164 & L & L & & 73 & 20 & 7 \\
DN177 & L & L & & 74 & 19 & 7 \\
NC5260 & I & L & & 57 & 29 & 14 \\
NE222 & I & I & & 35 & 36 & 29 \\
NC5271 & I & H & & 2 & 7 & 90 \\
MWH13 & H & H & & 26 & 36 & 38 \\
MWH5 & H & L & & 47 & 33 & 19 \\
NE308 & H & H & & 13 & 28 & 59 \\
NC11432 & H & H & & 6 & 17 & 77 \\
NE351 & H & H & & 2 & 6 & 92 \\
NC11505 & H & H & & 0 & 100 \\
\hline
\end{tabular}

${ }^{a}$ Final model with lesion number (Lesion $n$ ) and proportion necrotic area (PNA) as parameters.

${ }^{b}$ Disease damage categories of Weiland et al. $(41,42)$ : low (L), intermediate (I), or high $(\mathrm{H})$. Predicted damage categories were based on probability of placement given response to conidial inoculation.

$c$ Probability of placement in category. 
resistance evaluation under field conditions requires thousands of trees, at replicated field sites, measured over several years (Table 1). Plantation establishment costs are proportional to the number of planted cuttings, routine maintenance, pest control, irrigation, and fertilization costs (12). Savings can be achieved by reducing the overall number of clones tested by eliminating the most susceptible clones prior to field testing. The nonwounded greenhouse screening protocol, described above, would facilitate this process.

The consistency in predictive ability of results obtained by inoculation of wounds by Weiland et al. (41) and from conidial inoculation in this study may provide clues as to the type of resistance mechanism being evaluated. In both cases, it is likely that postpenetration resistance among clones is being compared. If this is the case, then both inoculation assays are likely to provide similar predictions of long-term field performance. The results from this study and the correlation between wounded and nonwounded inoculations reported by LeBoldus et al. (15) support this hypothesis. Furthermore, the reliability of the conidial inoculation protocol presents an opportunity, initially proposed by Newcombe and Ostry (25), to elucidate the genetic mechanism of Septoria canker resistance. Newcombe and Ostry (25), in a field study conducted in Minnesota and Iowa, evaluated Septoria canker resistance in a three-generation pedigree of $P$. deltoides $\times P$. trichocarpa $\mathrm{L}$. and found evidence supporting the recessive inheritance of Septoria canker resistance. However, due to disease escape and variation in pathogen virulence, they could not conclude that resistance was conferred by a single gene. As a result, they suggested that further testing of the hypothesis be conducted in a greenhouse (25). A greenhouse assay, similar to that described above, would ensure that trees were inoculated with a single-spore isolate of known virulence, at a specific concentration and set volume of inoculum, eliminating the sources of variability, disease escape, and variation in pathogen virulence described in the study by Newcombe and Ostry (25).

Continued evaluation of clones selected for scale-up based on field observations or responses to inoculations are warranted. For example, clone NM6 was placed in the low canker damage category by Weiland et al. (41) based on previous reports $(1,13,18,24,41)$ and was placed in the low category based on response to inoculation in the current study. There has been a report of high incidence and severity of canker disease damage to that clone in the field in Wisconsin (40) and commercial plantings of NM6 have been severely impacted in Minnesota (J. LeBoldus, personal communication). The reasons for these discrepancies are unclear. The role of environmental conditions in disease development may offer a potential explanation. For example, Maxwell et al. (20) reported an effect of water stress on Septoria canker disease severity of clone NM6. Similar effects of water stress on disease severity and response to wounding have been reported in other systems $(5,19,23,30)$. The role of environmental conditions in disease development needs to be clarified in order to better understand this phenomenon; however, this was beyond the scope of this study.

Conidial inoculation of nonwounded seedlings can be integrated into hybrid poplar breeding programs to accurately predict the long-term disease impact categories of the most resistant and susceptible clones. Compared with other methods, this procedure is faster, less resource intensive, allows combinations of isolates to be used simultaneously, and does not circumvent potential resistance mechanisms by wounding. This procedure is currently being used by the hybrid poplar breeding program at the University of Minnesota-Duluth to screen hybrids prior to deployment in the field (unpublished data).

\section{Acknowledgments}

This project was supported by the United States Department of Agriculture (USDA) National Institute of Food and Agriculture USDA-NIFA-RIPM 201234103-19771 grant to J. LM. LeBoldus and G. R. Stanosz. A GRA was provided to R. Qin from North Dakota State University-Agricultural Experiment Station. We thank J. Stanosz for her help in collecting poplar cuttings at the University of Wisconsin-Madison Arlington-Agricultural Research Station, and B. McMahon and B. Berguson at the University of Minnesota-Duluth Natural Resource Research Institute for help with isolate collections.

\section{Literature Cited}

1. Abrahamson, L. P., White, E. H., Nowak, C. A., Briggs, R. D., and Robinson, D. J. 1990. Evaluating hybrid poplar clonal growth potential in a threeyear-old genetic selection field trial. Biomass 21:101-114.

2. Allison, P. D. 2012. Logistic Regression Using SAS Theory and Application, 2nd ed. SAS Publishing, Cary, NC.

3. Balatinecz, J. J., and Kretschmann, D. E. 2001. Properties and utilization of poplar wood. Pages 277-291 in: Poplar Culture in North America. D. I. Dickmann, J. G. Isebrands, J. E. Eckenwalder, and J. Richardson, eds. NRC Research Press, National Research Council of Canada, Ottawa, ON, Canada.

4. Bier, J. E. 1939. Septoria canker of introduced and native hybrid poplars. Can. J. Res. 17:195-204

5. Biggs, A. R., Davis, D. D., and Merrill, W. 1983. Cutting development and restriction of wound-associated infection in Populus. Can. J. Plant Pathol. 5:269-272.

6. Callan, B. E., Leal, I., Foord, B., Dennis, J. J., and van Oosten, C. 2007. Septoria musiva isolated from cankered stems in hybrid poplar stool beds, Fraser Valley, British Columbia. Pac. Northwest Fungi 2:1-9. Online publication. doi:10.2509/pnwf.2007.002.007

7. Dickmann, D. I. 2001. An overview of the genus Populus. Pages 1-42 in: Poplar Culture in North America. D. I. Dickmann, J. G. Isebrands, J. E. Eckenwalder, and J. Richardson, eds. NRC Research Press, National Research Council of Canada, Ottawa, ON, Canada.

8. Eckenwalder, J. E. 1996. Systematics and evolution of Populus. Pages 7-32 in: Biology of Populus and Its Implications for Management and Conservation. R. F. Stettler, H. D. Bradshaw, Jr., P. E. Heilman, and T. M. Hinckley, eds. NRC Research Press, National Research Council of Canada, Ottawa, ON, Canada.

9. Esau, K. 1969. The Phloem. Gebruder Borntreger, Berlin, Stuttgart, Germany.

10. Feau, N., Hamelin, R. C., Vandecasteele, C., Stanosz, G. R., and Bernier, L. 2005. Genetic structure of Mycosphaerella populorum (anamorph Septoria musiva) populations in north-central and northeastern North America. Phytopathology 95:608-616.

11. Gyenis, L., Anderson, N. A., and Ostry, M. E. 2003. Biological control of Septoria leaf spot disease of hybrid poplar in the field. Plant Dis. 87:809813.

12. Hansen, E., Moore, L., Netzer, D., Ostry, M., Phipps, H., and Zavitkovski, J. 1983. Establishing intensively cultured hybrid poplar plantations for fuel and fiber. U. S. Dep. Agric. For. Serv. Gen. Tech. Rep. NC-78.

13. Hansen, E. A., Ostry, M. E., Johnson, W. D., Tolsted, D. N., Netzer, D. A Berguson, W. E., and Hall, R. B. 1994. Field performance of Populus in short-rotation intensive culture plantations in the north-central U. S. U. S Dep. Agric. For. Serv. Res. Pap. NC-320.

14. Krupinsky, J. M. 1989. Variability in Septoria musiva in aggressiveness Phytopathology 79:413-416.

15. LeBoldus, M. J., Blenis, P. V., and Thomas, B. R. 2010. A method to induce stem cankers by inoculating non-wounded Populus clones with Septoria musiva spore suspensions. Plant Dis. 94:1238-1242.

16. LeBoldus, M. J., Blenis, P. V., Thomas, B. R., Feau, N., and Bernier, L. 2009. Susceptibility of Populus balsamifera to Septoria musiva: a field study and greenhouse experiment. Plant Dis. 93:1146-1150.

17. Littell, R. C., Milliken, G. A., Stroup, W. W., Wolfinger, R. D., and Schabenberger, O. 2006. SAS for Mixed Models, 2nd ed. SAS Publishing, Cary, NC.

18. Lo, M. H., Abrahamson, L. P., White, E. H., and Manion, P. D. 1995. Early measures of basal area and canker disease predict growth potential of some hybrid poplar clones. Can. J. For. Res. 25:1113-1118.

19. Long, R., Bowersox, T. W., and Merrill, W. 1986. Artificial inoculation of Populus hybrids with Septoria musiva. Can. J. For. Res. 16:405-407.

20. Maxwell, D. L., Kruger, E. L., and Stanosz, G. R. 1997. Effects of water stress on colonization of poplar stems and excised leaf disks by Septoria musiva. Phytopathology 87:381-388.

21. McNeil Technologies, Inc. 2009 Assessment of biomass energy opportunities for Red Lake band of Chippewa Indians. Final report 2005. U.S. Department of Energy, Tribal Energy Program DE-FG36-03G013123. Online publication. http://apps1.eere.energy.gov/tribalenergy/pdfs/redlakeosfinal.pdf

22. Mercker, D. 2007. Short rotation woody crops for biofuels. Univ. Tenn. Agric. Ext. Serv. SP-702-C.

23. Mullick, D. B. 1977. The nonspecific nature of defense in bark and wood during wounding, insect, and pathogen attack. Recent Adv. Phytochem. 11:395-441.

24. Netzer, D. A., Tolsted, D. N., Ostry, M. E., Isebrands, J. G., Riemenshneider, D. E., and Ward, K. T. 2002. Growth, yield, and disease resistance of $7-$ to 12-year-old poplar clones in the north central United States. U. S. Dep. Agric. For. Serv. Gen. Tech. Rep. NC-229.

25. Newcombe, G., and Ostry, M. 2001. Recessive resistance to Septoria stem canker of hybrid poplar. Phytopathology 91:1081-1084.

26. Ostry, M. E. 1987. Biology of Septoria musiva and Marssonina brunnea in 
hybrid Populus plantations and control of Septoria canker in nurseries. Eur. J. For. Pathol. 17:158-165.

27. Ostry, M. E., and McNabb, H. S., Jr. 1983. Disease of intensively cultured hybrid poplars: a summary of recent research in the north central region. U. S. Dep. Agric. For. Serv. Gen. Tech. Rep. NC-91.

28. Ostry, M. E., and McNabb, H. S., Jr. 1985. Susceptibility of Populus species and hybrids to disease in the north central United States. Plant Dis. 69:755757.

29. Ostry, M. E., Wilson, L. F., and McNabb, H. S., Jr. 1989. Impact and control of Septoria musiva on hybrid poplars. U. S. Dep. Agric. For. Serv. Gen. Tech. Rep. NC-133.

30. Romakkaniemi, P., and Poteri, M. 1987. Effects of some environmental conditions on the response of birch bark to wounding. Eur. J. For. Pathol. 17:298-304.

31. Sannigrahi, P., Ragauskasm, A. J., and Tuskan, G. A. 2010. Poplar as a feedstock for biofuels: a review of compositional characteristics. Biofuels Bioprod. Bioref. 4:209-226.

32. Schreiner, E. J. 1972. Procedure for selection of hybrid poplar clones for commercial trials in the northeastern region. Pages 108-116 in: 19th Proc. Northeastern For. Tree Improve. Conf.

33. Sivanesan, A. 1990. Mycosphaerella populorum. CMI Descr. Pathogenic Fungi Bacteria No. 988. Commonwealth Mycological Institute, Kew, UK

34. Stettler, R. F., Zsuffa, L., and Wu, R. 1996. The role of hybridization in the genetic manipulation of Populus. Pages 87-112 in: Biology of Populus and Its Implications for Management and Conversation. R. F. Stettler, H. D.
Bradshaw, Jr., P. E. Heilman, and T. M. Hinckley, eds. NRC Research Press, National Research Council of Canada, Ottawa, ON, Canada.

35. Stoffle, R. 1998. Short rotation woody crops: hybrids poplar. In: Proc. Conf. Improv. For. Prod. Timber Vol. 1.

36. Strobl, S., and Fraser, K. 1989. Incidence of Septoria canker of hybrid poplars in eastern Ontario. Can. Plant Dis. Surv. 69:109-112.

37. Thompson, G. E. 1941. Leaf-spot diseases of poplars caused by Septoria musiva and S. populicola. Phytopathology 31:241-254.

38. Ward, K. T., and Ostry, M. E. 2005. Variation in Septoria musiva and implications for disease resistance screening of poplars. Plant Dis. 89:1077-1082.

39. Waterman, A. M. 1946. Septoria canker of poplars in the United States. U. S. Dep. Agric. Circ. No. 947, Washington, DC

40. Weiland, J. E., and Stanosz, G. R. 2003. Epidemic of canker disease on hybrid poplar clone NM6. (Abstr.) Phytopathology 93:S89.

41. Weiland, J. E., Stanosz, J. C., and Stanosz, G. R. 2003. Prediction of longterm canker disease damage from the responses of juvenile poplar clones to inoculation with Septoria musiva. Plant Dis. 87:1507-1514.

42. Weiland, J. E., Stanosz, J. C., and Stanosz, G. R. A. 2005. Test of the validity of screening poplar clone for long-term canker disease damage by responses to inoculation with Septoria musiva. Plant Notes. 51:6-15.

43. Yang, D., Bernier, L., and Dessureault, M. 1994. Biological control of Septoria leaf spot of poplar by Phaeotheca dimorphospora. Plant Dis 78:821-825.

44. Zalasky, H. 1978. Stem and leaf spot infections caused by Septoria musiva and S. populicola on poplar seedlings. Phytopathology 59:43-50. 